\title{
A Study of Emotional Intelligence and Resilience Among Medical Interns - to emphasize Inclusion in the Medical Curriculum
}

\author{
Ira Shukla $^{1}$, Ameya Gaikwad ${ }^{2}$, Shubhangi S. Dere ${ }^{3}$, Abhishek Gupta $^{4}$, Rakesh Ghildiyal ${ }^{5}$ \\ ${ }^{1}$ Intern, MGM Medical College \& Hospital, Navi Mumbai, India \\ ${ }^{2}$ Intern, MGM Medical College \& Hospital, Navi Mumbai, India \\ ${ }^{3}$ Assistant Professor, Department of Psychiatry, MGM Medical College, Navi Mumbai, India \\ ${ }^{4}$ Resident, Department of Psychiatry, MGM Medical College, Navi Mumbai, India \\ ${ }^{5}$ Professor \& Head, Department of Psychiatry, MGM Medical College, Navi Mumbai, India \\ Corresponding author: Shubhangi Dere \\ Email - shubhangi.dere@gmail.com
}

\begin{abstract}
Background: Emotional Intelligence (EI), influencing one's interpersonal and communication skills can help doctors to improve their patient care and clinical outcomes. Medical interns are young, naïve professionals who face numerous psychological stressors during their internship. Encouraging resilience can alleviate negative effects of stressors improving their professionalism during internship and further medical profession. The aim of the study was to study the pattern and correlation of emotional intelligence and resilience among medical interns.

Method: Total 109 medical interns, consenting to participate in the study were included in the study after obtaining informed consent and institutional ethics committee approval. Participants were asked to fill in a Google survey form which consisted of emotional intelligence and resilience scale and the responses were tabulated and analysed using descriptive analysis and t-test.

Results: Majority of the interns of both genders had poor scores and needed improvement on all the domains of Emotional Intelligence. Total resilience score was found to be comparable for both male and female interns. Total resilience score was found to be significantly lower in those who needed improvement in emotional intelligence.

Conclusions: Female interns had better EI as compared to male interns. Poor emotional intelligence was associated with poor resilience score in our study. Majority of the interns reported inadequate training on EI and resilience in current undergraduate medical education. Increasing awareness about emotional intelligence and resilience in interns can be an essential component in their medical curriculum.
\end{abstract}

Keywords: Emotional Intelligence, Psychological Resilience, Education, Medical, Undergraduate.

(Paper received $-7^{\text {th }}$ August 2020, Peer review completed $-5^{\text {th }}$ November 2020)

(Accepted $-6^{\text {th }}$ November 2020)

\section{INTRODUCTION}

Emotional Intelligence (EI) is defined as the capacity to be aware of, control, and express one's emotions, and to handle interpersonal relationships judiciously and empathetically. EI is an important component of cognitive ability that facilitates interpersonal behaviour. It facilitates the effective integration of emotion and cognition, resulting in intelligent use of emotions and the use of emotions to improve thought processes [1]. Bar-On defined EI as a set of emotional, personal, and social abilities, skills, and competencies that impact one's ability to cope with daily demands. Available studies have highlighted association of EI to physical and psychological health influencing one's ability to cope with stress and demands, less professional burnout resulting in more success, effective leadership skills, across a variety of professions [2]. In the medical field too, it has been noted that EI plays an important role in the professional success of medical doctors [3]. EI can have a positive influence on domains of medical practice including doctor-patient relationship, 
empathy, communication skills, patient satisfaction, diagnostic skills, patient compliance, decrease in lawsuits, teamwork, professional burnout, organizational commitment, and medical leadership. Additionally, academic success among medical students has also been linked to higher EI levels [4-5].

Resilience is an ability of an individual to show positive adaptation and to bounce back even when they experience significant trauma or adversity [6-7]. It is the capacity to cope positively with stress. Resilience plays an important role in enhancing academic success, to overcome challenges and stress in professional life [8]. Resilience can enhance abilities of an individual like better adaptability in stressful environment through problem-solving skills and flexibility. These skills can be essential to make graduating medical students a confident and efficient doctor in their professional life. Thus, 'resilience' is an important aspect to be studied in this population [9]. Resilience also includes other factors such as the capacity to make realistic plans, having self-confidence and a positive self-image, developing communication skills and the capacity to manage strong feelings and impulses [10].

Current medical profession is facing lots of challenges like increased disease burden with increasing lifespan, technology misguiding patients and families leading to their challenging and demanding behaviour, lawsuits, violence towards the doctor etc. A doctor needs to develop a balancing ability to handle these challenges and at the same time, maintaining better communication with patients, relatives and the team. This process itself can result in higher burn-out with the medical profession. It is proposed that a good EI and resilience can protect the medical professional from developing burn-out. There is a growing research highlighting importance of EI and resilience in the success of a health-care professional.

The traditional medicine has been criticised to be less patient-centric where health-care workers were encouraged to preserve an emotional distance from their patients in order to maintain a certain degree of objectivity [11]. It's only recently, however, there has been a shift in patient-care approach toward breaking down barriers of communication between patients and health care practitioners, with emphasis of more empathic approach. In modern medicine, the focus is on improving the trusting relationship between doctor and a patient. Hence, developing good EI, resilience and communication skills becomes essential in order to improve patient satisfaction to build mutual understanding and trust with the treating doctor.

\section{Aims \& Objectives}

1. To study the pattern of emotional intelligence in medical interns

2. To study overall resilience in medical interns

3. To study association between emotional intelligence and resilience

\section{METHODOLOGY}

This was a descriptive cross-sectional study conducted at a tertiary care private teaching medical college and hospital. It was a one-time assessment of medical interns at the end of their compulsory rotatory postings. Total of 109 medical interns, fulfilling inclusion and exclusion criteria were enrolled in the study after obtaining ethics committee approval from institutional ethics committee and informed consent from the participants using complete enumeration. The participants were explained about the study objectives and a Google survey form using validated scales for EI and resilience to self-administer via e-mail. The responses obtained through Google survey form were tabulated and analyzed using Microsoft Excel Version 13. Descriptive statistics: mean, standard deviation, frequency and percentages were calculated. Chi square test were used as test of significance at $p$ value cut off of 0.05 .

\section{Materials}

Proforma: A detailed semi-structured proforma to record the name, age, sex \& ethnicity of the participant. The Google survey form included 5 questions to assess knowledge and attitude of medical interns towards concept and need EI and Resilience in medical education. These questions were:

- 'Are you aware of the term 'Emotional Intelligence \& Resilience?'

- 'Have you officially been introduced or received training in the domains of EI and Resilience?'

- 'Have you been suffering from any psychological health issues currently or in the past?' 
- 'Have you witnessed or experienced psychological health issues in your family/ close relatives/ friends?'

- 'Do you think introduction and training about EI and Resilience is required in medical profession?'

\section{Scales Used -}

1. Emotional Quotient Self-Assessment Checklist: It consists of 30 statements, five each for the domains of self-awareness, self-confidence, self-control, empathy, motivation and socialcompetency. Each question is scored based on a 5-point Likert scale ranging from 1 to 5 (virtually never $=1$ to virtually always $=5$ ). The total score was the sum of all 6 domain scores. The minimum and maximum scores for each domain were 5 and 25 respectively and a cut -off value for good EI is 20 in each domain, the score below which needs improvement in the respective domain. This questionnaire has good psychometric properties in terms of reliability (Cronbach's alpha $=0.82$ ) [12].

2. The Connor-Davidson resilience scale (CD-RISC-25): CD-RISC contains 25 items, all of which carry a 5-point range of responses, as follows: not true at all (0), rarely true (1), sometimes true (2), often true (3), and true nearly all of the time (4). The item response is based on how the subject has felt over the past month. The total score ranges from $0-100$. Higher the score, greater is the resilience. Internal consistency of the scale reported is 0.90 [13].

\section{RESULTS}

Total 109 medical interns were enrolled for our study. On studying socio-demographic profile, it was observed that majority (two-thirds) of them were females and mean age of interns was found to be 23.35 years with range of 22 to 28 years $(S D=0.843)$. (Table 1$)$

\begin{tabular}{|l|l|l|l|}
\hline \multicolumn{2}{|c|}{ Socio-demographic Parameters } & Frequency & Percentage \\
\hline Mean Age & \multicolumn{2}{|l|}{23.35 years (SD=0.843) } \\
\hline Sex & Females & 73 & $66.97 \%$ \\
\hline & Males & 36 & $33.03 \%$ \\
\hline
\end{tabular}

Table 1: Socio-demographic parameters

When interns were asked whether they knew the term "Emotional Intelligence\& Resilience"; majority of them $(88.07 \%, \mathrm{~N}=96)$ reported to be aware while $4.58 \%(\mathrm{~N}=5)$ of them were not aware and rest of $7.35 \%$ $(\mathrm{N}=8)$ were not sure about the term. Majority of the interns $(87.16 \%, \mathrm{~N}=95)$ claimed that they have not been officially introduced or received training in the domains of emotional intelligence.

Nearly three fourth reported that psychological disorder was not experienced by them (77.98\%) but had witnessed their family members/ close relatives or friend suffering through one(72.48\%) either currently or in the past. Almost half (48.56\%) of the interns felt that introduction and training about emotional intelligence and resilience is required in medical profession.

\section{Domains of EI compared with Gender}

On comparing domains of emotional intelligence gender- wise, it was observed that majority of males and females needed improvement on all the domains. Among interns having normal EI score on the scale, it was observed that the percentage of female interns was higher compared to male interns on all domains except 'total self-control'. However, this gender-wise comparison of EI score was not statistically significant.

(Table 2) 


\begin{tabular}{|l|l|l|l|l|l|}
\hline \multirow{2}{*}{ Domains of Emotional Intelligence } & \multicolumn{2}{l|}{ Male } & \multicolumn{2}{l|}{ Female } & p-value \\
\cline { 2 - 6 } & $\begin{array}{l}\text { Need } \\
\text { improvement }\end{array}$ & $\begin{array}{l}\text { Normal } \\
\text { EI }\end{array}$ & $\begin{array}{l}\text { Need } \\
\text { improvement }\end{array}$ & Normal EI & \\
\hline Domain 1 (Self- Awareness) & $29(80.6 \%)$ & $7(19.4 \%)$ & $55(75.3 \%)$ & $18(24.7 \%)$ & 0.543 \\
\hline Domain 2 (Empathy) & $27(75.0 \%)$ & $9(25.0 \%)$ & $48(65.8 \%)$ & $25(34.2 \%)$ & 0.327 \\
\hline Domain 3 (Self- Confidence) & $30(83.3 \%)$ & $6(16.7 \%)$ & $58(79.5 \%)$ & $15(20.5 \%)$ & 0.629 \\
\hline Domain 4 (Motivation) & $28(77.8 \%)$ & $8(22.2 \%)$ & $54(74.0 \%)$ & $19(26.0 \%)$ & 0.665 \\
\hline Domain 5 (Total Self- Control) & $29(80.6 \%)$ & $7(19.4 \%)$ & $60(82.2 \%)$ & $13(17.8 \%)$ & 0.836 \\
\hline Domain 6 (Social Competency) & $30(83.3 \%)$ & $6(16.7 \%)$ & $56(76.7 \%)$ & $17(23.3 \%)$ & 0.426 \\
\hline
\end{tabular}

Table 2: Domains of EI compared with Gender

(Test used: Chi-Square test, Chi-Square value: Domain 1: 0.371, Domain 2: 0.960, Domain 3: 0.234, Domain 4: 0.187, Domain 5: 0.043, Domain 6: 0.635. $\mathrm{df}=1$ )

\section{Resilience}

The mean resilience score found was 65.79 ( $\mathrm{SD}=13.324)$. The mean resilience score was observed to be comparable for both male and female interns. (Table 3 )

\begin{tabular}{|l|l|l|l|}
\hline & Mean & SD & P value \\
\hline Female & 65.51 & 14.044 & 0.755 \\
\cline { 1 - 3 } Male & 66.36 & 11.900 & \\
\hline
\end{tabular}

Table 3: Resilience scores

(Test used: Independent Samples t-test, t-test value: $-0.313, \mathrm{df}=107$ )

Domains of Emotional Intelligence compared with Total Resilience

On comparing total resilience score with all the domains of emotional intelligence, it was observed that the mean resilience scores were higher for those who had normal Emotional Intelligence Scale and didn't need any improvement. This comparison of resilience with emotional intelligence was observed to be statistically significant on all the domains of EI scale. (Table 4)

\begin{tabular}{|c|c|c|c|c|}
\hline \multicolumn{2}{|c|}{ Domains of Emotional Intelligence } & \multicolumn{2}{|c|}{ Total Resilience } & \multirow[t]{2}{*}{ p value } \\
\hline & & Mean & SD & \\
\hline \multirow[t]{2}{*}{ Domain 1 (Self-Awareness) } & Need Improvement & 62.23 & 11.895 & \multirow[t]{2}{*}{$0.001^{*}$} \\
\hline & Normal EI & 77.76 & 10.764 & \\
\hline \multirow[t]{2}{*}{ Domain 2 (Empathy) } & Need Improvement & 61.51 & 11.953 & \multirow[t]{2}{*}{$0.001^{*}$} \\
\hline & Normal EI & 75.24 & 11.271 & \\
\hline \multirow[t]{2}{*}{ Domain 3 (Self-Confidence) } & Need Improvement & 62.83 & 11.823 & \multirow[t]{2}{*}{$0.001^{*}$} \\
\hline & Normal EI & 78.19 & 12.274 & \\
\hline \multirow[t]{2}{*}{ Domain 4 (Motivation) } & Need Improvement & 61.84 & 11.374 & \multirow[t]{2}{*}{$0.001^{*}$} \\
\hline & Normal EI & 77.78 & 11.663 & \\
\hline \multirow[t]{2}{*}{ Domain 5 (Total self-control) } & Need Improvement & 62.75 & 11.753 & \multirow[t]{2}{*}{$0.001^{*}$} \\
\hline & Normal EI & 79.30 & 11.576 & \\
\hline \multirow[t]{2}{*}{ Domain 6 (Social Competency) } & Need Improvement & 62.47 & 11.848 & \multirow[t]{2}{*}{$0.001^{*}$} \\
\hline & Normal EI & 78.22 & 11.160 & \\
\hline
\end{tabular}

(* denotes $\mathrm{p}$ value $<0.005$ i.e. statistically significant)

Table 4: Domains of Emotional Intelligence compared with Total Resilience

(Test used: Independent Samples t-test. T-test values - Domain 1: 5.852, Domain 2: -5.653, Domain 3: 0.5311, Domain 4: -0.6276, Domain 5: -5.704, Domain 6: $-5.731 . \mathrm{df}=107$ ) 


\section{DISCUSSION}

Even though only minority of the medical interns were unaware of the term 'EI' and 'Resilience', most of them agreed upon the fact that their current medical education did not cover training for the EI and resilience and that the training for the same is essential in a medical curriculum.

This is only recently that with newer recommendations of competency based medical education by Medical Council of India, medical schools have begun integrating soft-skills development in their curriculum. EI and resilience training as a part of the soft skills can contribute to development of core skills of a medical professional. It has been proposed that understanding needs of a graduating medical intern can help design the curriculum and address the budding medical professional's overall emotional wellness, which can further enhance their clinical experience, and perhaps even improve patient outcomes [14].

In India, the Vision 2015 document of the Medical Council of India, the apex body in charge of curriculum development for medical education in the country, focused on the AETCOM module, which is the Attitude, Ethics and Communication module, in order to impart education on communication skills, empathy, emotional intelligence, resilience and ethics [15].

\section{Emotional Intelligence}

Emotional intelligence contributes significantly to communication skills and empathy by enabling a healthcare worker to understand patient's, caregiver's and their own emotions, respond appropriately, to minimize inter-personal conflict while working in a team and improving outcome of patient care. Given significant importance placed on the quality of medical care, many researchers have recommended training of EI in medical curriculum to increase their professional and soft skills [16-19].

The percentage of normal EI scores on all domains of self- awareness, empathy, self-confidence, motivation and social-competency were higher in female interns as compared to males except for domain of total selfcontrol where, male interns scored better than the females, although, this gender-wise difference in EI scores was not statistically significant.

The concept of emotional intelligence is widely researched with emphasis on gender-wise difference, the findings of which suggest that women score better than men in terms of emotional understanding and expression, translating into better empathy and clinical care, whereas men do better than women when it comes to managing distressing emotions [20-21]. The widely available literature has highlighted that women tend to have better emotional understanding. They tend to understand, express emotions better than men and have a greater ability as regards to certain interpersonal skills. Women for instance, recognize other people's emotions better, are more perceptive and have greater empathy [22-24]. The superiority of female gender in emotional intelligence over males has been supported by biological theories too. Some evidence exists that certain areas of the brain dedicated to processing emotions could be larger in women than in men [25].

\section{Resilience}

In our study, resilience score was comparable in both the gender. This finding is in accordance with previous studies on resilience in medical students which reported that gender doesn't play a significant role in relation to resilience $[9,26]$. The concept of EI and resilience are inter-dependent with each ability complement to the other. Both EI and resilience together are required for better stress appraisal, stress management and to reduce professional burn-out. Wide research is available in association of EI and resilience with perceived stress. The available research suggests that university students with better emotional intelligence and resilience present lower perceived stress. Thus, improving emotional intelligence and resilience could prevent students from suffering perceived stress in higher education [27], considering high level of stress and burn-out in medical professions, it is essential to study EI and resilience in the budding medical graduates. When total resilience score was compared with the domains of emotional intelligence, it was observed that the mean resilience scores had significantly positive association with the emotional intelligence score across all domains. The resilience score was high in interns with good emotional intelligence. Consistent with our findings, the vast majority of research in the area shows that people with better EI have better resilience. Similar observations are reported by Schneider et al. [28], Magnano et al. [29] and Cejudo et al. [30] who 
demonstrated that EI facilitates stress resilience. Infact, the four EI abilities appeared to facilitate resilient stress responses including challenge appraisals, more positive and less negative affect, and challenge physiology. The components of EI can help in better stress-appraisal, emotional understanding, self-control, emotional expression, and emotional regulation, thus facilitating resilience. A study by Armstrong et al. [31] revealed that EI was related to psychological resilience. These authors concluded that having higher EI is adaptive in stressful circumstances resulting in better resilience.

It can be proposed that the undergraduate students with higher levels of EI were inclined to be more resilient, which may contribute to a decrease in perceived stress. The EI determines the perceived stress and also can act as a protective factor promoting stress-resiliency, plays a paramount role in the activation of strategies that could help in protecting psychological adjustment [32]. EI is thus postulated to buffer the effects of aversive events of stress in an individual. This hypothesis is supported by findings of a study by Armstrong [31] who observed that EI was negatively associated with events and distress. Most persons with higher EI scores reported that fewer stressful events continued to distress them. Importantly, individual differences in four EI dimensions were found to distinguish between the vulnerable. According to author, all the components of EI i.e. Emotional Self-Awareness, Emotional Expression, Emotional Self-Control and particularly, Emotional Self-Management determine the resilience and stress coping.

A study to investigate the relationship as well as the impact of Emotional Intelligence (EI) on to the perception of role stress of medical professionals in their organisational lives, observed that there was no significant difference in the level of EI and perceived role stress between genders, but significantly negative relationships of EI with organisational role stress for both the gender and the medical professionals as a whole [33]. This can be elaborated to understand that the stress understanding and coping as a component of resilience can be improved through the training on EI in medical professionals.

\section{Limitations}

The study was carried out in a small sample size in a single cohort of batch of interns. A study on different stages of medical education focussing on first-year, final year, interns and residency across multiple centres can create more generalizable results. Also, multiple correlates of the EI and Resilience apart from gender were not a part of study methodology.

\section{CONCLUSIONS}

EI score was higher in female interns whereas, the resilience score was comparable across both genders. Poor emotional intelligence was associated with poor resilience score in our study. Majority of the interns expressed inadequate training on EI and resilience in current undergraduate medical education. Newer Competency Based Medical Education can initiate training about emotional intelligence and resilience to enhance the communication skills, empathy, clinical skills, professionalism and stress management abilities of a graduating medical student. Medical education should focus on gender-specific innovative strategies to train medical students to understand, express and manage their emotions and to translate their EI into resilience and better clinical care.

\section{REFERENCES}

1. Mayer J, Salovey P, Caruso, DR. Emotional intelligence: theory, findings and implications. Psychol Inq 2004;15:197-215.

2. Bar-On R. The Bar-On model of emotional-social intelligence (ESI). Psicothema 2006;18(suppl):13-25.

3. Arora S, Ashrafian H, Davis R, Athanasiou T, Darzi A, Sevdalis N. Emotional intelligence in medicine: a systematic review through the context of the ACGME competencies. Med Educ 2010;44:749-64.

4. Czabanowska K, Malho A, Schröder-Bäck P, Popa D, Burazeri, G. Do we develop public health leaders? Association between public health competencies and emotional intelligence: a cross-sectional study. BMC Med Educ 2014;14:83. 
5. Naeem N, Van Der Vleuten C, Muijtjens AM, Violato C, Ali SM, Al-Faris EA, Hoogenboom R, Naeem N. Correlates of emotional intelligence: results from a multi-institutional study among undergraduate medical students. Medical Teacher 2014;36(sup1):S30-5.

6. Luthar SS, Cicchetti D. The construct of resilience: implication for interventions and social policies. Dev Psychopathol 2000;12(4):857-85.

7. Southwick S, Charney D. The Science of Mastering Life's Greatest Challenges. From 'Resilience' Cambridge University Press, New York; 2012.

8. Greenhill J, Fielke KR, Richards JN, Walker LJ, Walters LK. Towards an understanding of medical student resilience in longitudinal integrated clerkships. BMC Med Educ 2015;15:137.

9. Faye A, Tadke R, Gawande S, Kirpekar V, Bhave S, Pakhare A, et al. Assessment of resilience and coping in undergraduate medical students: A need of the day. J Educ Technol Health Sci 2018;5:36-44.

10. Linzer M, Visser MR, Oort FJ, Smets EM, McMurray JE, de Haes HC; Society of General Internal Medicine (SGIM) Career Satisfaction Study Group (CSSG). Predicting and preventing physician burnout: Results from the United States and the Netherlands. Am J Med 2001;111:170-8.

11. Brannick MT, Wahi MM, Arce M, Johnson HA, Nazian S, Goldin SB. Comparison of trait and ability measures of emotional intelligence in medical students. Med Educ 2009;43:1062-8.

12. Sterrett EA. The manager's pocket guide to emotional intelligence, 2nd Ed. Mumbai: Jaico Publishing House, 2004.

13. Connor KM, Davidson JRT. Development of a new resilience scale: The Connor-Davidson Resilience Scale (CD- RISC). Depression and Anxiety 2003;18:76-82.

14. Uchino R, Yanagawa F, Weigand B, Orlando JP, Tachovsky TJ, Dave KA, Stawicki SP. Focus on emotional intelligence in medical education: From problem awareness to system-based solutions. Int J Acad Med 2015;1:9-20

15. Modi JN, Gupta P, Singh T. Competency-based medical education, entrustment and assessment. Indian Pediatr 2015;52:413-20.

16. Zayapragassarazan Z, Kumar S. Emotional Intelligence and Medical Professionalism. NTTC Bulletin 2011; 18(2):3-4

17. Johnson DR. Emotional intelligence as a crucial component to medical education. Int J Med Educ 2015;6: 179-83.

18. Hojat M, Gonnella JS, Mangione S, Nasca TJ, Veloski JJ, Erdmann JB, et al. Empathy in medical students as related to academic performance, clinical competence and gender. Med Educ 2002;36:522-7.

19. Castro-Schilo L, Kee DW. Gender differences in the relationship between emotional intelligence and right hemisphere lateralization for facial processing. Brain Cogn 2010;73:62-7.

20. Ubaidi A. Is Emotional Intelligence a Need Skill for Health Care Provider. J Fam Med Dis Prev. 2018;4(1).

21. Sundararajan S, Gopichandran V. Emotional intelligence among medical students: a mixed methods study from Chennai, India. BMC Med Educ 2017;18:97

22. Tapia M, Marsh II GE. The effects of sex and grade point average on emotional intelligence. Psicothema 2006; 18:108-11.

23. Venkatappa KG, Shetty SC, Sparshadeep EM, Parakandy SB, Das SK. Gender differences in emotional intelligence among first year medical students. J Evol Med Dent Sci 2012;1(6):1256-62.

24. Sanchez-Nunez MT, Fernandez-Berrocal P, Montanes J, Latorre JM. Does emotional intelligence depend on gender? The socialisation of emotional competencies in men and women and its implications. Electr J Res Educ Psychol 2008;6(2):455-74.

25. Somaiya M, Kolpakwar S, Faye A, Kamath R. Study of mechanisms of coping, resilience and quality of life in medical undergraduates. Indian J Soc Psychiatry 2015;31:19-28.

26. Sarrionandia A, Ramos-Díaz E, Fernández-Lasarte O. Resilience as a Mediator of Emotional Intelligence and Perceived Stress: A Cross-Country Study. Front. Psychol 2018;9.

27. Schneider TR, Lyons JB, Khazon S. Emotional intelligence andresilience. Personal Indiv Diff 2015;55:909_ 14.

28. Magnano P, Craparo G, Paolillo A. Resilience and emotional intelligence: which role in achievement motivation. Int J Psychol Res 2016;9:9-20.

29. Cejudo J, López-Delgado ML, Rubio MJ. Emotional intelligence and resilience: its influence on life satisfaction in university students. Ann. Psychol 2016;46:51-7.

30. Armstrong AR, Galligan RF, Critchley CR. Emotional intelligence and psychological resilience to negative life events. Personal Indiv Diff 2011;51:331-6.

31. Hodzic S, Ripoll P, Costa H, Zenasni F. Are emotionally intelligent students more resilient to stress? The moderating effect of emotional attention, clarity and repair. Behav Psychol 2016;24:253-72. 
32. Singh SK, Singh S. Managing role stress through emotional intelligence: a study of Indian medico professionals," Int J Indian Cult Business Manage 2019;1(4):377-96.

$\star * * * * * * * * * * * * * * * * * * * * * * * * * * * * * * * * * * *$

Acknowledgements - We like to thank all participants who participated wholeheartedly in the study.

Conflict of Interest - Nil

Funding - Nil 